\title{
Assessment and Correction of Stress in Preterm Infants and Their Mothers
}

Iryna Sarapuk ( $\sim$ prostoirusya@ukr.net)

Horbachevsky Ternopil State Medical University

\section{Halyna Pavlyshyn}

Horbachevsky Ternopil State Medical University

\section{Research Article}

Keywords: preterm infants, stress, salivary cortisol, maternal stress

Posted Date: May 20th, 2021

DOl: https://doi.org/10.21203/rs.3.rs-508519/v1

License: (c) (1) This work is licensed under a Creative Commons Attribution 4.0 International License. Read Full License

Version of Record: A version of this preprint was published at Turkish Archives of Pediatrics on March 7th, 2022. See the published version at https://doi.org/10.5152/TurkArchPediatr.2022.21158. 


\section{Abstract}

The objective was to study the peculiarities of hormonal stress in preterm infants in the NICU and their mothers, and to investigate how skin-to-skin contact influences it. The study included 60 preterm infants with GA囚32 weeks who were treated in NICU and their mothers. The overall design was a baselineresponse design. Saliva was collected before (baseline) and after skin-to-skin contact to measure cortisol by enzyme immunoassay method. Infant baseline salivary cortisol level was $0.587[0.239 ; 1,714] \mu \mathrm{g} / \mathrm{dL}$. It was significantly higher in neonates who had invasive ventilation $(1.00[0.38 ; 2.44]) \mu \mathrm{g} / \mathrm{dL}$ compared to non-ventilated infants $(0.335[0.156 ; 1.236]) \mu \mathrm{g} / \mathrm{dL}, \mathrm{p}=0.022$; and positively correlated with the Apgar score at 1 st and 5th minutes $(r=-0.36 ; p=0.011$ and $r=-0.34 ; p=0.017)$ and duration of ventilation $(r=$ $0.70 ; p=0.0000)$. Maternal baseline salivary cortisol level was $0.212[0.123 ; 0.378] \mu \mathrm{g} / \mathrm{dL}$. There was significant decreasing of salivary cortisol after Kangaroo mother care with skin-to-skin contact in infants

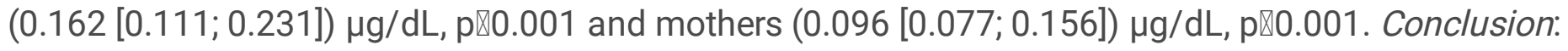
Preterm infants in the NICU and their mothers experience stress confirmed by the increased baseline cortisol levels. Kangaroo mother care with skin-to-skin contact reduces the stress and normalizes salivary cortisol levels in both infant and mother in the NICU.

\section{What Is Known}

Premature birth is accompanied by stress in infants due to their immaturity and presence of constant stressors of the NICU.

\section{What is New}

Preterm infants in the NICU and their mothers experience stress confirmed by the elevated baseline cortisol levels.

Kangaroo mother care with skin-to-skin contact reduces the stress and normalizes salivary cortisol levels in both infant and mother in the NICU.

\section{Introduction}

Premature birth is accompanied by stress in infants due to their immaturity and presence of constant stressors, which they are exposed to in the neonatal intensive care unit (NICU) from the first days of life $[1,2]$. Preterm neonates not only suffer from the diseases that often accompany premature birth, but are also exposed to many painful and invasive treatment procedures (intubation, suction of the endotracheal tube, blood sampling, intravenous catheters insertion, etc.) and daily care manipulations (diaper change, feeding, repositioning, weighing and hygienic care) together with the numerous environmental stimuli [ 1 , 3]. Premature newborns become hypersensitive to all stimuli when the number of daily manipulations is significant and they often occur one after another [2]. In this case infant experiences the routine care procedures as unpleasant and painful [4], and responds to them with signs of dysadaptation and stress, namely with the vital functions destabilization (tachycardia, desaturation, apnea), skin discoloration, 
disturbance of sleep-wake cycle, motor dysfunctions and sudden changes of muscle tone $[5,6]$. It is rather difficult to distinguish between stress and pain in the neonatal period. It is considered that all pain is stressful but not all stress is painful [7, 8]. Also, premature infants in NICU are usually separated from the mother, and this is the most important stressor for a child [1]. It has been proven that this severe stress stops when the baby returns to the mother [8].

When a child is born, stress helps him/her to adapt to extrauterine life, especially stabilizes the functioning of the respiratory and cardiovascular systems, induces lung maturation $[9,10]$. However, excessive stress experienced by an immature infant when the brain is particularly sensitive to environmental influences has both early and long-term consequences for the child's development. Prolonged excessive levels of cortisol stimulate a significant increase in glutamate levels, which contributes to overstimulation of neurons, reduce the connections between them, and leads to neuronal cell death [11], and thus contributes to learning and cognitive disabilities, memory and attention deficits, behavioral disorders [12].

Parents of preterm infants in the NICU also experience considerable stress due to anxiety, fear, powerlessness, and parental role alterations [8]. Mother-infant separation, breaking their natural relationship that occurs in utero and increases after childbirth are the strongest stressors for mothers. An important link between maternal psychological status and infant development has been proven $[13,14]$, and this emphasizes the important role of the mother in the child's development and the need to support a "mother-infant" relationship. Instead, the relationship between the mother and her infant in the NICU begins in difficult conditions for both of them - the mother is not physically and psychologically ready for the preterm birth, and the infant is immature and usually needs intensive treatment [8].

Considering the intensive stress in preterm infants and their parents in the NICU and its long-term side effects, it is necessary to use the stress-reducing methods in routine care. Kangaroo mother care with skin-to-skin contact (SSC) recommended for premature neonates, among many other benefits, can also minimize the negative effects of stress and mother-infant separation in the NICU $[3,15]$.

The objective of our study. The primary outcome was to study the peculiarities of hormonal stress in preterm infants in the NICU and their mothers by measuring salivary cortisol levels. The secondary outcome was to study the stress level patterns in preterm infants and their mothers in response to skin-toskin contact. The third outcome was to evaluate the correlation of infant and maternal stress and to investigate how SSC influences it.

\section{Patients And Methods}

Study Design and patients. The study included 60 preterm infants with gestational age less than 32 weeks. All studies were conducted in Ternopil Perinatal Center; infants were recruited from the neonatal intensive care unit, which is level III NICU. 
Prematurity (GA $\leq 32$ weeks) was the criteria for inclusion in this study. Exclusion criteria were the following: chromosomal disorders, congenital malformations, and absence of parents' consent.

The overall design was a baseline-response design. The baseline is defined as the state before the intervention (SSC) is introduced. The response refers to the stress response in relation to the intervention (SSC) introduced. All individuals act as their controls between the baseline level and the study intervention results. All infants included in the study had an SSC with their mother under the nurses' supervision. Naked neonates were positioned prone on the mother's bare chest, dressed only with diapers. Mothers were provided with comfortable chairs and advised to wear front open gowns. All hospital policies and procedures for SSC were followed to ensure the safety of infants during the SSC interventions.

Sample collection and cortisol assay. Saliva was collected before (baseline) and after skin-to-skin contact. Saliva specimens were collected from 1:00 to 3:00 pm. due to the diurnal rhythm of maternal cortisol. Saliva samples were collected without the usage of any salivation stimulating agents. Infant saliva samples were collected using cotton sponges, after that was extracted from the sponges by centrifugation (2 minutes at $2000 \times \mathrm{g}$ ). Mother's samples were collected with Salivette (Sarstedt, Rommelsdorft, Germany). After extraction samples were frozen and stored at $-20^{\circ} \mathrm{C}$. Enzyme Immunoassay for the quantitative determination of free cortisol in human saliva was used to analyze cortisol concentrations in the samples (IBL International GmbH, Hamburg, Germany).

Ethics. The study was approved by the Local ethical committee and the informed consent was obtained from all the participants who took part in the study.

Statistics. All computations were performed using StatSoft STATISTICA Version 13 (Tulsa, OK). Quantitative data are presented as the median and interquartile range (IQR; 25th to 75th percentiles). For qualitative parameters, absolute and relative frequencies are presented. The Mann-Whitney U-test (for two independent groups) was used to compare numerical data. Proportions were compared between the two groups using the Chi-square test. Significance was assumed at $p<0.05$. Correlations were analyzed using Spearman's rank correlation coefficient.

\section{Results}

A total of 60 infants with a gestational age of $31.0[29.0 ; 32.0]$ weeks were enrolled in the study. There were $30(50 \%)$ boys and $30(50 \%)$ girls. Table 1 summarizes the patients involved in the study group. 
Table 1

Summary of the patients involved in the study

\begin{tabular}{|c|c|c|}
\hline & Statistical index & $\begin{array}{l}\text { Study group, } \\
n=60\end{array}$ \\
\hline Gestational age, weeks & $\mathrm{Me}[\mathrm{Lq} ; \mathrm{Uq}])$ & $31.0[29.0 ; 32.0]$ \\
\hline Birth weight (grams) & $\mathrm{Me}[\mathrm{Lq} ; \mathrm{Uq}])$ & $\begin{array}{l}1475.0 \\
{[1225.0 ; 1775.0]}\end{array}$ \\
\hline Percentile of BW for GA & $\mathrm{Me}[\mathrm{Lq} ; \mathrm{Uq}])$ & $53.5[31.5 ; 70.0]$ \\
\hline SGA & $\mathrm{n}(\%)$ & $5(8.1 \%)$ \\
\hline Apgar score at 1 st min & $\mathrm{Me}[\mathrm{Lq} ; \mathrm{Uq}])$ & $6.0[5.0 ; 7.0]$ \\
\hline Apgar score at 5th min & $\mathrm{Me}[\mathrm{Lq} ; \mathrm{Uq}])$ & $7.0[6.0 ; 7.0]$ \\
\hline $\begin{array}{l}\text { Gravida } \\
1 \\
\geq 2\end{array}$ & $\begin{array}{l}\text { n (\%) } \\
\text { n (\%) }\end{array}$ & $\begin{array}{l}24(40.0) \\
36(60.0)\end{array}$ \\
\hline $\begin{array}{l}\text { Parity } \\
1 \\
\geq 2\end{array}$ & $\begin{array}{l}\text { n (\%) } \\
\text { n (\%) }\end{array}$ & $\begin{array}{l}29(48.3) \\
31(51.7)\end{array}$ \\
\hline $\begin{array}{l}\text { Delivery mode: } \\
\text { vaginal delivery } \\
\text { C-section }\end{array}$ & $\begin{array}{l}\text { n (\%) } \\
\text { n (\%) }\end{array}$ & $\begin{array}{l}18(30.0) \\
42(70.0)\end{array}$ \\
\hline Primary resuscitation & $\mathrm{n}(\%)$ & $35(58.3)$ \\
\hline RDS & $\mathrm{n}(\%)$ & $48(80.0)$ \\
\hline Early-onset sepsis & $\mathrm{n}(\%)$ & $20(33.3)$ \\
\hline Invasive ventilation & $\mathrm{n}(\%)$ & $18(30.0)$ \\
\hline CPAP & $\mathrm{n}(\%)$ & $24(40.0)$ \\
\hline Nasal cannulas & $\mathrm{n}(\%)$ & $18(30.0)$ \\
\hline
\end{tabular}

Infant baseline salivary cortisol level was $0.587[0.239 ; 1,714] \mu \mathrm{g} / \mathrm{dL}$. It was significantly higher in neonates who underwent invasive ventilation $(1.00[0.38 ; 2.44]) \mu \mathrm{g} / \mathrm{dL}$ compared to non-ventilated infants $(0.335[0.156 ; 1.236]) \mu \mathrm{g} / \mathrm{dL}, \mathrm{p}=0.022$; and was positively correlated with the Apgar score at $1 \mathrm{st}$ and 5 th minutes (Spearman $r=-0.36 ; p=0.011$ and Spearman $r=-0.34 ; p=0.017$ ) and the duration of invasive ventilation (Spearman $r=0.70 ; p=0.0000)$, Fig. $1-3$. 
No significant correlations were found between the infant baseline cortisol level and gestational age $(\mathrm{p}=$ $0.366)$, birth weight $(p=0.912)$, and chronological age $(p=0.957)$. There was no difference in the baseline salivary cortisol depending on the gender $(p=0.98)$, mode of delivery $(p=0.96)$, need for primary resuscitation $(p=0.118)$, incidence of respiratory distress syndrome $(p=0.626)$ and early-onset sepsis $(p$ $=0.278)$.

Maternal baseline salivary cortisol level was $0.212[0.123 ; 0.378] \mu \mathrm{g} / \mathrm{dL}$. It was higher in mothers who gave birth by caesarean section $(0.222[0.110 ; 0.387] \mu \mathrm{g} / \mathrm{dL}$ compared to vaginal delivery $(0.124$ [0.082; $0.168]) \mu \mathrm{g} / \mathrm{dL}, \mathrm{p}=0.036$; Fig. 4 . There was no difference in maternal baseline cortisol level depending on the infant gender $(p=0.99)$, gestational age $(p=0.361)$, the number of fetuses $(p=0.204)$, infant need of ventilation $(p=0.114)$.

There was significant decreasing of salivary cortisol after Kangaroo mother care with skin-to-skin contact, both in infants $(0.162[0.111 ; 0.231]) \mu \mathrm{g} / \mathrm{dL}, \mathrm{p} \otimes 0.001$ and their mothers $(0.096[0.077 ; 0.156]) \mu \mathrm{g} / \mathrm{dL}$, $\mathrm{p} \varangle 0.001$; Figs. 5 and 6 . Only $5(8.3 \%)$ infants and $6(10.0 \%)$ mothers had increased salivary cortisol after skin-to-skin contact $(p=0.144$ in infants and $p=0.005$ in mothers).

We found no significant correlations between maternal and infant cortisol levels before $(r=+0.13 ; p=$ $0.470)$ and after skin-to-skin contact $(r=+0.31 ; p=0.147)$.

\section{Discussion}

Our study found that preterm infants in NICU and their mothers experience stress, which is confirmed with the increased baseline cortisol levels, both in children and mothers. Extremely and very preterm neonates undergo repeated painful treatment and caregiving procedures during a period of rapid brain development and stress system programming $[1,11]$. This is a period when their sensory systems are immature and thus the imbalance of excitatory versus inhibitory processes can lead to increased nociceptive signaling in the central nervous system [16]. The immature central nervous system of preterm infants is particularly vulnerable to intensive external stimuli, and in combination with mother's separation and pleasant stimuli absence (mother's touch, voice, odor) has been associated with altered brain microstructure, hormonal status disbalance $[11,16]$. A lot of researches showed stress related to procedural neonatal pain during heel lance, eye-screening examination, physical examination, and caregiving interventions that was associated with the increased levels of cortisol $[2,8,17,18]$. Our study was not associated with some exact procedural pain, as the sample collection was performed against the background of all routine procedures.

The present study revealed inverse correlation between the baseline cortisol level and Apgar score at 1st and 5th minutes $(r=-0.36 ; p=0.011$ and $r=-0.34 ; p=0.017)$, and duration of invasive ventilation (Spearman $r=0.70 ; p=0.000$ ). Low Apgar scores in premature newborns are considered to reflect more developmental immaturity than fetal distress, and such Apgar score criteria as muscle tone, reflex irritability, and respiratory effort are developmentally determined [19, 20]. As preterm neonates with low Apgar scores tend to be less mature, therefore, our results of correlations between Apgar score and 
cortisol levels may indicate the increased response of the preterm infant to stress due to the higher degree of immaturity [20]. Also, preterm newborns with low Apgar scores receive primary resuscitation in the delivery room and intensive neonatal care during the first hours of life [1,3] that can serve as an additional trigger for an intense stress response with a long-lasting effect.

To the best of our knowledge data about the correlation between Apgar score and stress intensity in preterm infants are absent. However, it is known that mortality, multisystem morbidity, incidences of neonatal interventions, and complications are significantly higher in newborns of gestational age less than 37 weeks with low Apgar score [19, 20].

The invasive ventilation period can be described as a very stressful and uncomfortable period [22], and the less mature the infant, the longer ventilation he/she needs [23]. There is no data on how painful and stressful invasive ventilation is itself, but it is obvious that it is accompanied by plenty of potential painful interventions like intubation and sometimes reintubation, often endotracheal suctioning, skin lesions due to the adhesive materials changes. Routine use of sedatives seems insufficient to prevent high stress scores [22]. Also, various modes of ventilation can potentially increase the level of stress. In particular, infants additionally suffer from the need to "fight the ventilator" at mandatory asynchronous modes [24]. It was also shown a reduction in stress hormone concentration, namely adrenaline, over a short time period in preterm infants with gestational age less than 32 weeks when mode of ventilation was changed from conventional mandatory ventilation to patient triggered ventilation [25]. With the wide introduction of high frequency ventilation in the neonatal practice the reports of increased stress manifestation, namely discomfort, agitation, restlessness, increased pain scores and decreased sleep time appeared in literature [22], however, there are no data on laboratory determination of hormonal status in children with high frequency and conventional ventilation.

Stress and pain experienced in the neonatal period have been suggested to influence the HPA axis in the later period [26]. Thus, chronic activation of the HPA axis in early life is considered to result in long-term programming of the HPA axis to function in a dysregulated manner [3]. Higher baseline salivary cortisol that positively correlated to the amount of experienced pain has been reported in preterm infants at eight months corrected age as compared with the full-term healthy neonates [4]. Thus, the higher salivary cortisol level, found in the present study, could be an early sign of a disturbance in the HPA system related to stress in preterm infants in the NICU. Also, stress in preterm newborns has been associated with longterm consequences as disorders in cognitive, motor, and behavioral development, anxiety, depression, autism spectrum disorder, high blood pressure, and metabolic syndrome $[12,16,27]$. Therefore, preterm infants who had long-term mechanical ventilation and low Apgar scores require special support in stress mitigation and follow-up monitoring to prevent early and long-term effects of prolonged stress hormones elevations.

The current study showed that mothers of preterm infants in the NICU also experienced high levels of stress. These findings coincide with other researches $[12,14]$ that pointed the mother-infant separation and inability to perform maternal role were the greatest stress factor for mothers [14]. Most of these 
studies examined the behavioral manifestations of maternal stress using questionnaires, and there are only a few data on hormonal status evaluation in mothers after preterm birth and admission of their infants to NICU $[8,12]$.

Increased cortisol levels in mothers who gave birth by cesarean section indicate that mode of delivery is associated with maternal endocrine stress response. Orovou et al. stated that $40 \%$ of women experienced cesarean section, especially emergency cesarean section (70\%), as a traumatic childbirth experience [28]. Some studies pointed out the emergency cesarean section as a risk factor for the development of postpartum psychological disorders [28, 29]. Several authors showed a great correlation between emergency cesarean section and posttraumatic stress disorder compared to other types of birth [30,31].

Stress in the NICU leads to the search for evidence-based interventions that would effectively reduce stress and its negative consequences for infants and their mothers. Kangaroo Mother Care with skin-toskin contact is one of the developmental care approaches that has been used to mitigate the physiological and behavioral stress and treat the negative consequences of maternal separations from infants [32]. Our study provides valuable insights about laboratory confirmation of positive SSC effect on infant and maternal hormonal stress. Cortisol level decreasing in infants indicates that SSC has buffering effects on stress reactivity. Constantly receiving the warmth from the mother's skin and familiar olfactory stimuli, having autonomic stability and calm sleep, feeling comfort and safety on mother's chest and hear her heartbeat together with the incredible power of maternal love and tender embrace may facilitate the maturation of the HPA axis and decrease infant stress reactivity during SSC [33,34]. Our results are consistent with the theory that maternal contact and gentle touch have an impact on the infant's brain system that manages stress [33].

The stress regulatory effect of SSC was investigated by other authors. Thus, Lyngstad et al. found that SSC ameliorates the stress associated with diaper change in premature infants with gestational age 2834 weeks [18]. Castral et al. investigated the salivary cortisol level in infants before and after heel prick that was performed at SSC and they found no increase in the cortisol level [35].

Similar to research in premature infants, maternal salivary cortisol levels after SSC significantly reduced when compared with baseline levels in our study that coincides with the results of other authors [12, 36]. Decreased feelings of stress and anxiety state in mothers of preterm infants during and after SSC were also reported in the researches that studied behavioral patterns of maternal stress. Mothers often say that the inability to hold and hug the child causes the most stress. Therefore, skin-to-skin contact, which allows the mother to hold the baby on her chest, feel his/her every movement and heartbeat will undoubtedly bring the mother not only pleasure, but also will help to mitigate the negative effects of parental role alteration, enhance the feelings of the maternal parental role [37]. Also, it has been proven that the feeling of comfort and stress reduction by mothers is continued even after SSC that confirms a prolonged effect of SSC on maternal stress $[37,38]$. Therefore, it is also necessary to study the duration of the beneficial effect of SSC on maternal hormonal status. 
Some infants $(8.3 \%)$ and mothers $(10.0 \%)$ in our study responded to SSC with the increase of cortisol levels. We have found some researches that pointed to either increased or decreased cortisol levels during the SSC - a decrease was revealed in $45.7 \%$ and an increase in $54.3 \%$ of newborns [7]. We have much fewer "nonresponders" to stress buffer effects of SSC, which requires further study of these features. Therefore, it is valuable to identify the unique needs of each baby. According to the developmental care principles, it is important to provide the infant with opportunities for rest and recovery and to individualize the technique of this manipulation in keeping with the capabilities and needs of each child. Some babies may be ready for SSC soon after birth and others may need to have several days or even weeks in an incubator or cot because they are unwell and unstable [39]. Each infant's status and need should be assessed before SSC begins to ensure that the procedure is beneficial to each baby. It is also necessary to prepare the mother for this intervention and make sure that she feels confident enough to hold her infant quickly after birth, or maybe the mother will need time to learn her infant and become more comfortable with the environment [39].

Environmental factors, such as sharing the time and environment, are considered to increase the correlation between maternal and child cortisol levels $[8,40]$. We found no significant correlations between maternal and infant cortisol levels before and after skin-to-skin contact. The lack of correlation may be explained by the fact that mothers were not constantly present with infants, did not stay overnight at the NICU, and were not involved in all caregiving procedures around the clock $[8,41]$. The objective support to these data was provided by Morelius et al. who compared the influence of FamilyCentered Care, when parents were constantly present with infants in relation to the standard care by measuring the salivary cortisol before and after nappy change as a stressful intervention. No significant differences regarding cortisol reactivity were found; however, there was a correlation between the basal and reactive cortisol levels in infants and mothers in the Family-Centered Care Group compared to the standard care group [8]. It is considered that the human touch and constant closeness to the parent day and night facilitate the preterm infant biological brain development and the HPA axis maturation [41]. These findings indicate that parents must be present and stay close to their infants to be able to cherish and support the baby, and thus, achieve the mother-infant synchronization and stress reduction.

\section{Conclusion}

Preterm infants in the NICU and their mothers experience stress confirmed by the elevated baseline cortisol levels. Baseline cortisol level is significantly higher in neonates who had invasive ventilation, and is positively correlated with the duration of ventilation and with the Apgar score. The level of maternal baseline cortisol depends on the type of delivery and is higher at cesarean section.

Kangaroo mother care with skin-to-skin contact reduces the stress and normalizes salivary cortisol levels in both infant and mother in the NICU. Only a small number of infants and mothers responded to SSC with increased cortisol levels, indicating the need to individualize the technique of this intervention according to the capabilities and needs of each child and the readiness of each mother. 
No significant correlation was found between maternal and child cortisol levels before and after skin-toskin contact, indicating the need for not only regular skin-to-skin contact but also long-term rooming-in in the NICU.

\section{Declarations}

Funding: The study was funded by the Ministry of Health of Ukraine.

Conflict of interest: The authors declare that they have no conflict of interest.

Availability of data and material: The data that support the findings of this study are available from the corresponding author, Iryna Sarapuk, upon reasonable request.

Code Availability: N/A

AUTHOR CONTRIBUTIONS: Iryna Sarapuk contributed to the study conception and design, data collection and analysis, wrote the first draft and commented on previous versions of the manuscript

Halyna Pavlyshyn contributed to the study conception and design, data collection and analysis, wrote the first draft and commented on previous versions of the manuscript.

All authors read and approved the final manuscript.

Ethics approval statement: The study was approved by the Local ethical committee of the I. Horbachevsky Ternopil National Medical University (protocol N 49 issued 17.10.2018).

Consent to participate: the informed consent was obtained from all the participants who took part in the study.

\section{Consent for publication: N/A}

\section{References}

1. D'Agata AL, Sanders MR, Grasso DJ, Young EE, Cong X, McGrath JM (2017) Unpacking the burden of care for infants in the NICU. Infant Mental Health Journal 38:306-317. https://doi.org/ 10.1002/imhj.21636

2. Rebelato CTC, Stumm EMF (2019) Analysis of pain and free cortisol of newborns in intensive therapy with therapeutic procedures. BrJP São Paulo 2(2):159-65. DOI 10.5935/25950118.20190029

3. Pados BF (2019) Physiology of Stress and Use of Skin-to-Skin Care as a Stress-Reducing Intervention in the NICU. Nurs Womens Health23(1):59-70. doi: 10.1016/j.nwh.2018.11.002.

4. Grunau RE (2020) Personal perspectives: Infant pain-a multidisciplinary journey. Paediatric and Neonatal Pain 2(2):50-57. https://doi.org/10.1002/pne2.12017 
5. Als H, McAnulty GB (2011) The Newborn Individualized Developmental Care and Assessment Program (NIDCAP) with Kangaroo Mother Care (KMC): Comprehensive Care for Preterm Infants. Curr Womens Health Rev 7(3):288-301. doi:10.2174/157340411796355216.

6. Wang YW, Chang YJ (2015) Theoretical Development and Research Trends in Developmental Care. Hu li za zhi The journal of nursing62(5):89-95. org/10.6224/JN62.5.89

7. Janevski MR, Vujicic AD, Dukic SM (2016) Salivary cortisol as a biomarker of stress in mothers and their low birth weight infants and sample collecting challenges. J Med Biochem 35:118-122.

8. Mörelius E, Örtenstrand A, Theodorsson A, Frostell A (2015) A randomized trial of continuous skin-toskin contact after preterm birth and the effects on salivary cortisol, parental stress, depression, and breastfeeding. Early Human Development 91(1):63-70.

http://dx.doi.org/10.1016/j.earlhumdev.2014.12.005

9. McCance KL, Huether SE. Pathophysiology: The biologic basis for disease in adults and children (7th ed.). 2014. St. Louis, MO: Elsevier

10. Hillman N, Kallapur SG, Jobe A (2012) Physiology of Transition from intrauterine to Extrauterine Life. Clin Perinatol 39(4):769-783. doi:10.1016/j.clp.2012.09.009.

11. Mooney-Leber SM, Brummelte S (2017) Neonatal pain and reduced maternal care: Early-life stressors interacting to impact brain and behavioral development. Neuroscience 342:21-36. https:// doi.org/10.1016/j.neuroscience.2016.05.0012017

12. Cong X, Ludington-Hoe SM, Hussain N, Cusson RM, Walsh S, Vazquez V et al (2015) Parental oxytocin responses during skin-to-skin contact in pre-term infants. Early Hum Dev 91(7):401-6. doi: 10.1016/j.earlhumdev.2015.04.012.

13. Di Blasio P, Camisasca E, Miragoli S, lonio C and Milani L (2017) Does maternal parenting stress mediate the association between postpartum PTS symptoms and children's internalizing and externalizing problems? A longitudinal perspective. Child and Youth Care Forum 1-17.

14. Ionio C, Mascheroni E, Colombo C, Castoldi F, Lista G (2019) Stress and feelings in mothers and fathers in NICU: identifying risk factors for early interventions. Prim Health Care Res Dev 20:e81. doi: $10.1017 /$ S1463423619000021

15. Conde-Agudelo A, Díaz-Rossello JL (2014) Kangaroo mother care to reduce morbidity and mortality in low birth weight infants. Cochrane Database of Systematic Reviews 2014, Issue 4. Art. No.: CD002771. DOI: 10.1002/ 14651858.CD002771.pub3.

16. Vinall J, Grunau RE 92014) Impact of repeated procedural pain-related stress in infants born very preterm. Pediatr Res 75(5):584-7.

17. Kahraman A, Başbakkal Z, Yalaz M, Sözmen EY (2018) The effect of nesting positions on pain, stress and comfort during heel lance in premature infants. Pediatrics and Neonatology 59(4):352359.

18. Lyngstad LT, Tandberg BS, Storm H, Ekeberg BL, Moen A (2014) Does skin-to-skin contact reduce stress during diaper change in preterm infants? Early Human Development 90(4):169-172. http://dx.doi.org/10.1016/j.earlhumdev. 2014.01.011 
19. American Academy of Pediatrics. Committee on Fetus and Newborn, American College of Obstetricians and Gynecologists Committee on Obstetric Practice (2015) The Apgar score. Pediatrics 136:819-822.

20. Li F, Wu T, Lei X, Zhang H, Mao M, Zhang J (2013) The Apgar Score and Infant Mortality PLOS ONE 8(7):e69072.

21. Phalen AG, Kirkby S, Dysart K (2012) The 5-minute Apgar score: survival and short-term outcomes in extremely low-birth-weight infants. J Perinat Neonatal Nurs 26(2):166-71. doi:

10.1097/JPN.0b013e31825277e9.

22. Wielenga JM (2008) Stress and discomfort in the care of preterm infants: A study of the Comfort Scale and the Newborn Individualized Developmental Care and Assessment Program (NIDCAPß) in a Dutch level III NICU.

23. Knight AK, Smith AK, Conneely KN, Dalach P, Loke YJ, Cheong JL (2018) Relationship between epigenetic maturity and respiratory morbidity in preterm infants. J Pediatr 198:168-173.e2. doi:10.1016/j.jpeds.2018.02.074.

24. Claure N, Bancalari E (2007) New modes of mechanical ventilation in the preterm newborn: evidence of benefit. Arch Dis Child Fetal Neonatal Ed 92:F508-F512. doi: 10.1136/adc.2006.108852

25. Baumer JH (2001) Patient-triggered ventilation in premature neonates. Acta Pñ diatr. Suppl 436: 2224.

26. Brummelte S, Chau CM, Cepeda IL, Degenhardt A, Weinberg J, Synnes AR, et al (2015) Cortisol levels in former preterm children at school age are predicted by neonatal procedural pain-related stress. Psychoneuroendocrinology 51:151-63.

27. Victoria NC, Murphy AZ (2016) The long-term impact of early life pain on adult responses to anxiety and stress: Historical perspectives and empirical evidence. Experimental Neurology 275(Pt.2):261273. https://doi.org/10.1016/ j.expneurol.2015.07.017

28. Orovou E, Dagla M, latrakis G, Lykeridou A, Tzavara C, Antoniou E (2020) Correlation between Kind of Cesarean Section and Posttraumatic Stress Disorder in Greek Women. Int. J. Environ. Res. Public Health 17:1592. doi:10.3390/ijerph17051592

29. Xie R, Lei J, Wang S, Xie H, Walker M, Wen SW (2011) Cesarean section and postpartum depression in a cohort of Chinese women with a high cesarean delivery rate. J. Women's Health 20:1881-6.

30. Schwab W, Marth C, Bergant AM (2012) Post-Traumatic Stress Disorder Post Partum. Geburtshilfe Frauenheilkd 72:56-63.

31. Söderquist J, Wijma B, Thorbert G, Wijma K (2009) Risk Factors in Pregnancy for Post-Traumatic Stress and Depression after Childbirth. BJOG Int. J. Obstet. Gynaecol 116:672-680.

32. Bergman NJ (2019) Birth practices: Maternal-neonate separation as a source of toxic stress. Birth Defects Research 1-23. https://doi.org/10.1002/bdr2.1530

33. Ludington-Hoe SM (2015) Skin-to-Skin Contact: A Comforting Place With Comfort Food. MCN Am J Matern Child Nurs 40(6):359-66. doi: 10.1097/NMC.0000000000000178. 
34. Cong X, Cusson RM, Walsh S, Hussain N, Ludington-Hoe SM, Zhang D (2012) Effects of skin-to-skin contact on autonomic pain responses in preterm infants. J Pain 13(7):636-45. doi: 10.1016/j.jpain.2012.02.008.

35. Castral TC, Warnock F, Dos Santos CB, Dare MF, Moreira AC, Antonini SR et al (2015) Maternal mood and concordant maternal and infant salivary cortisol during heel lance while in kangaroo care. Eur $\mathrm{J}$ Pain 19(3):429-38.

36. Neu M, Hazel NA, Robinson J, Schmiege SJ, Laudenslager M (2014) Effect of holding on coregulation in preterm infants: a randomized controlled trial. Early Hum Dev 90(3):141-7. doi: 10.1016/j.earlhumdev.2014.01.008.

37. Lisanti AJ, Demianczyk AC, Costarino A, Vogiatzi MG, Hoffman R, Quinn R et al (2021) Skin-to-Skin Care is Associated with Reduced Stress, Anxiety, and Salivary Cortisol and Improved Attachment for Mothers of Infants With Critical Congenital Heart Disease. JOGNN 50:40-54. https://doi.org/10.1016/j.jogn.2020.09.154

38. Harrison TM, Brown R (2017) Autonomic Nervous System Function after a Skin-to-Skin Contact Intervention in Infants with Congenital Heart Disease. J Cardiovasc Nurs 32(5):E1-E13. doi: $10.1097 / J C N .0000000000000397$.

39. Pallás-Alonso CR, Losacco V, Maraschini A, Greisen G, Pierrat V, Warren I at al (2012) European Science Foundation Network. Parental involvement and kangaroo care in European neonatal intensive care units: a policy survey in eight countries. Pediatr Crit Care Med 13(5):568-77. doi: 10.1097/PCC.0b013e3182417959

40. Örtenstrand A, Westrup B, Brostrom EB, Sarman I, Akerstrom S, Brune T et al (2010) The Stockholm Neonatal Family Centered Care Study: effects on length of stay and infant morbidity. Pediatrics 125(2):e278-85.

41. Cheng C, Franckb LS, Yec XY, Hutchinsonc SA, Leea SK, O'Brien (2019) Evaluating the effect of Family Integrated Care on maternal stress and anxiety in neonatal intensive care units. J Reprod Infant Psychol 10:1-14. doi: 10.1080/02646838.2019.1659940. Online ahead of print.

\section{Figures}



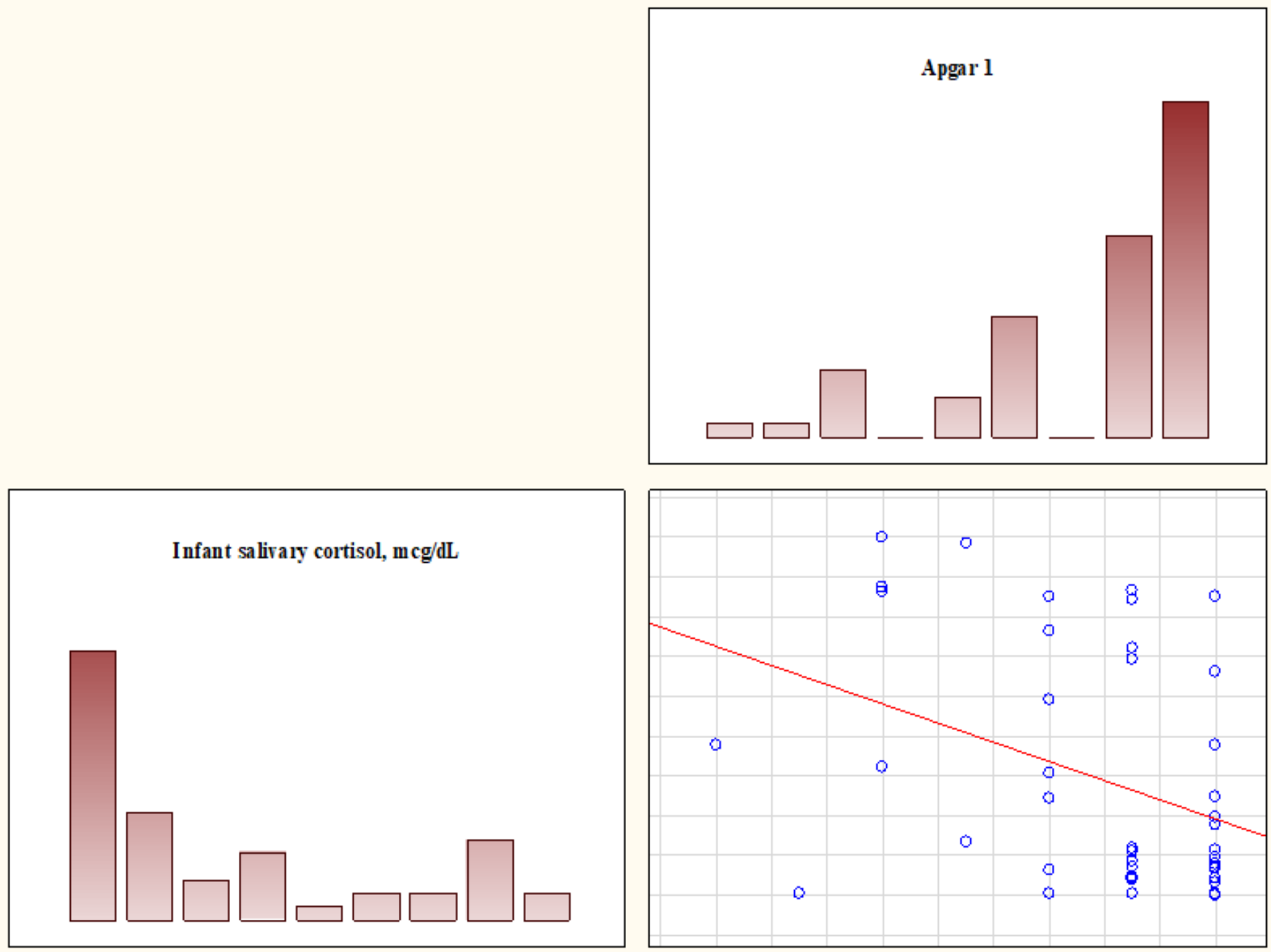

Figure 1

Correlation between infant salivary cortisol levels and Apgar score at 1st min. 

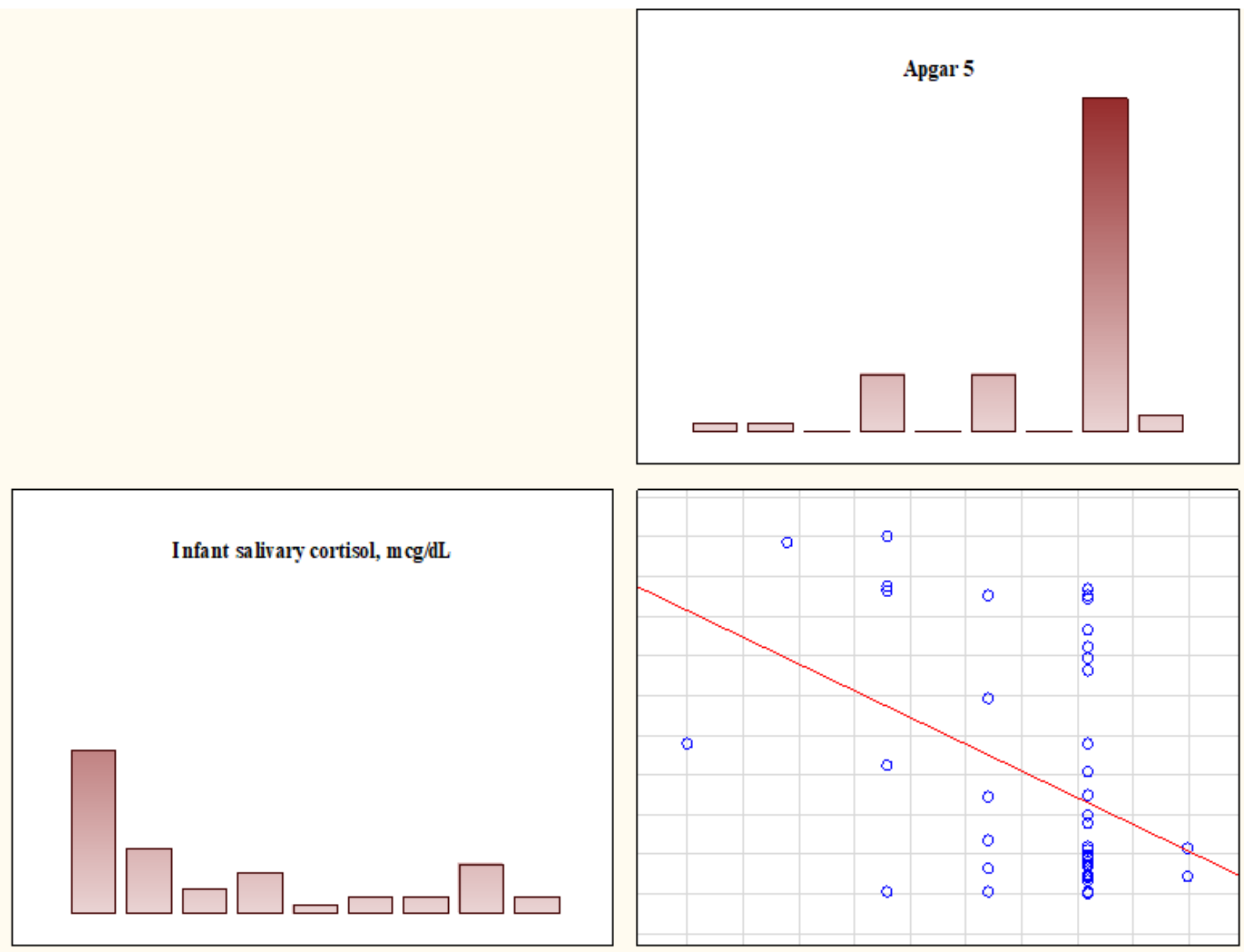

Figure 2

Correlation between infant salivary cortisol levels and Apgar score at $5 \mathrm{~min}$. 
Duration of ventilation, days
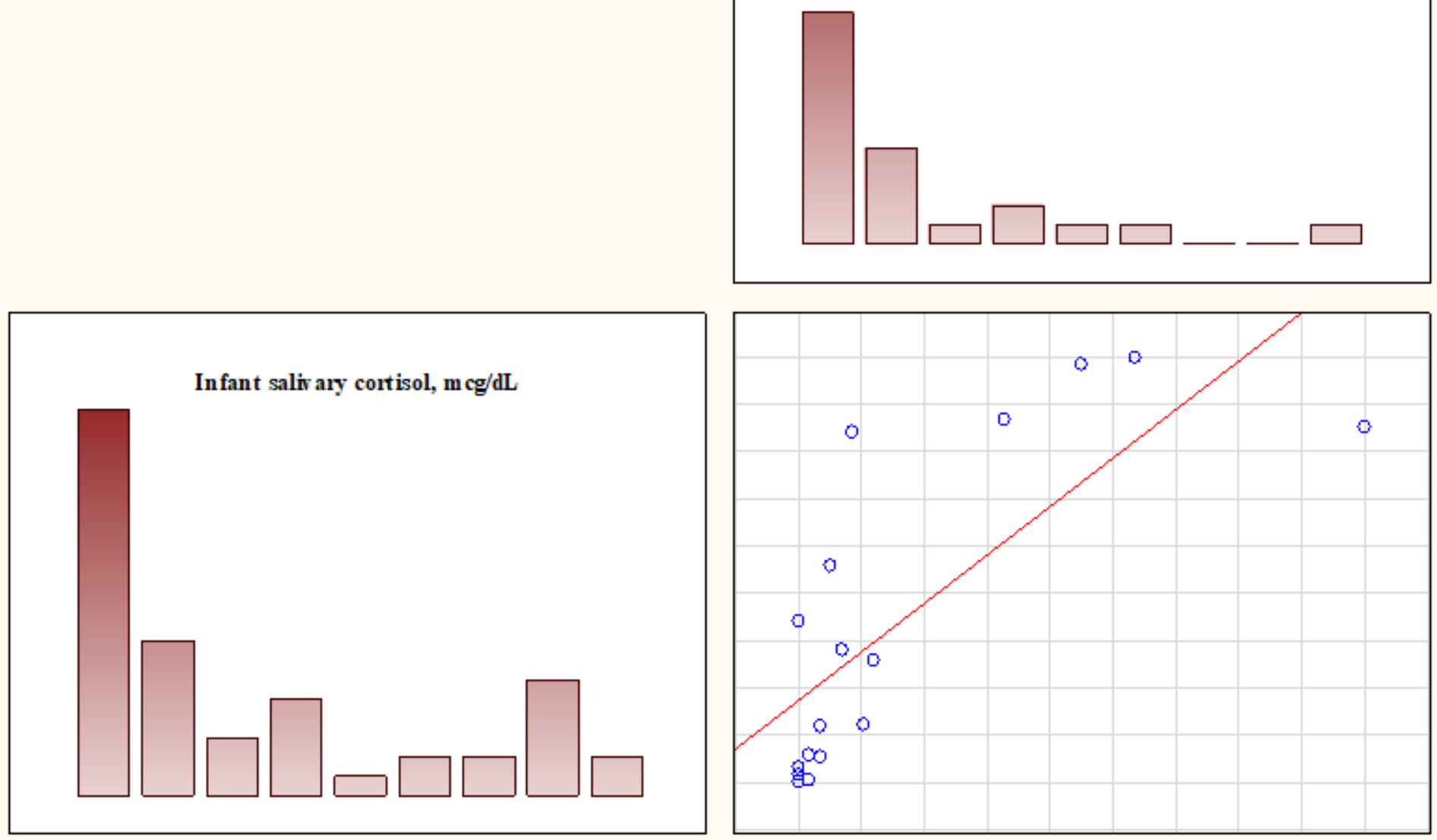

Figure 3

Correlation between infant salivary cortisol levels and duration of invasive ventilation 


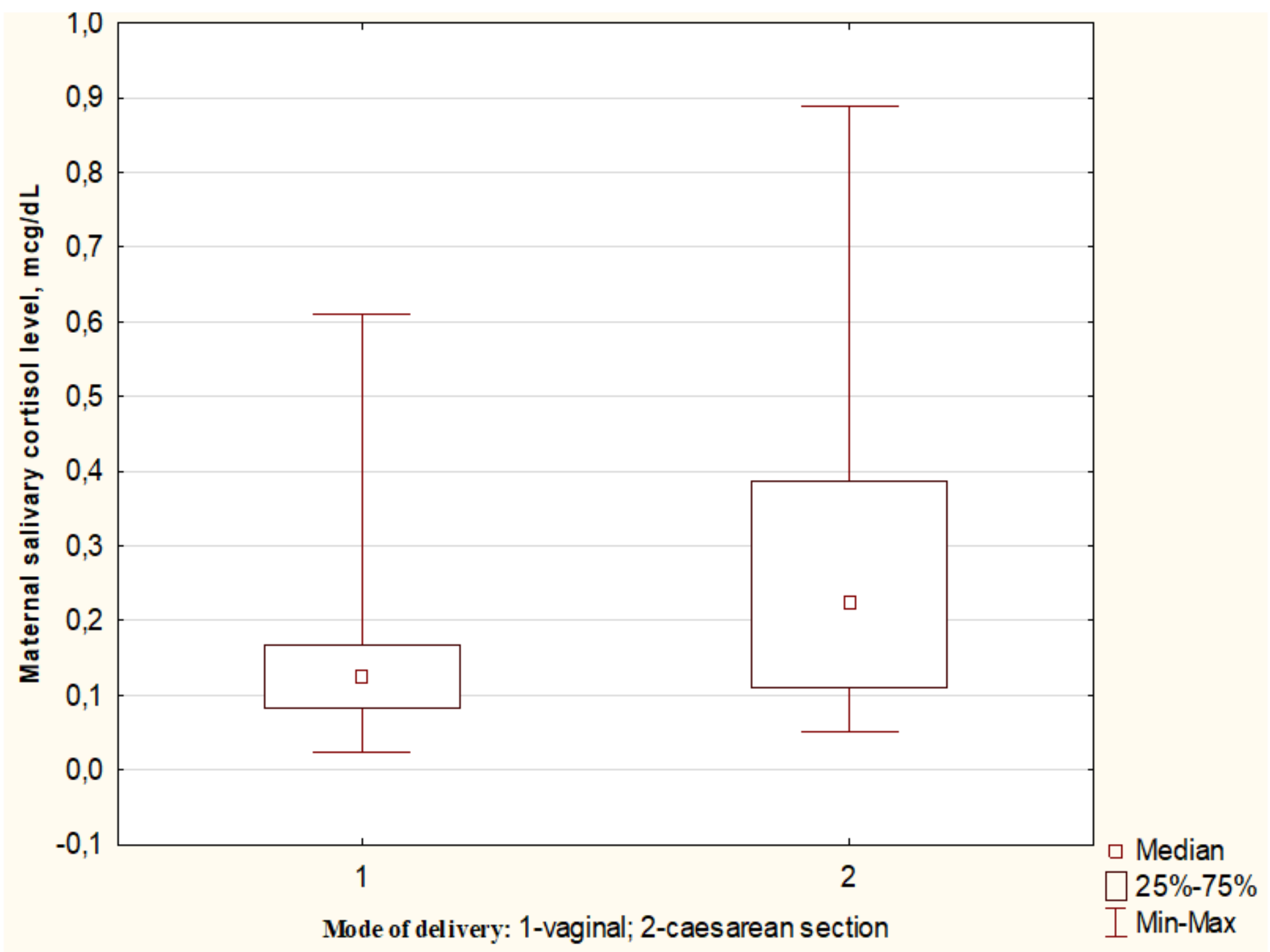

Figure 4

Maternal salivary cortisol levels depending on mode of delivery. 


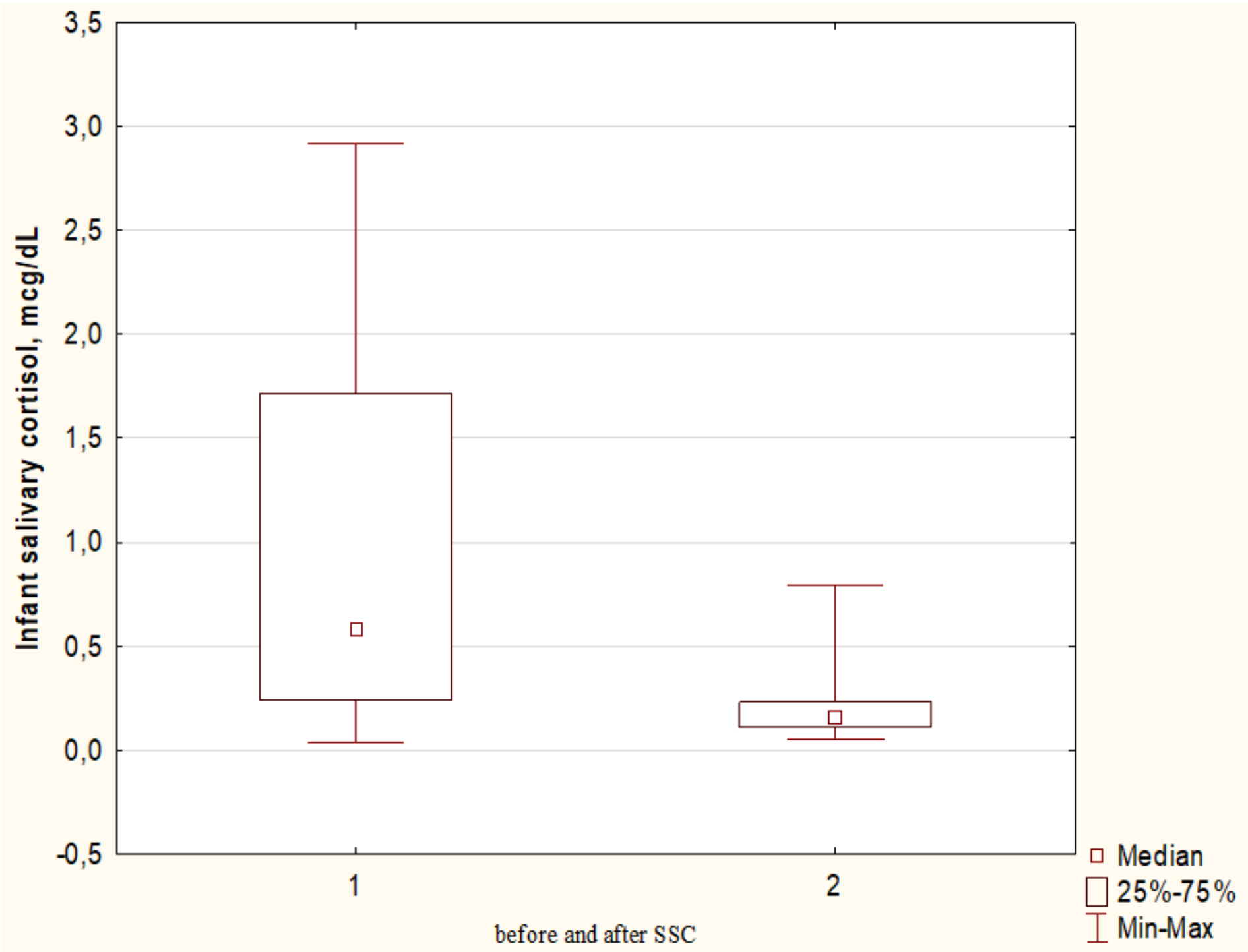

Figure 5

Infant salivary cortisol levels before and after skin-to-skin contact 


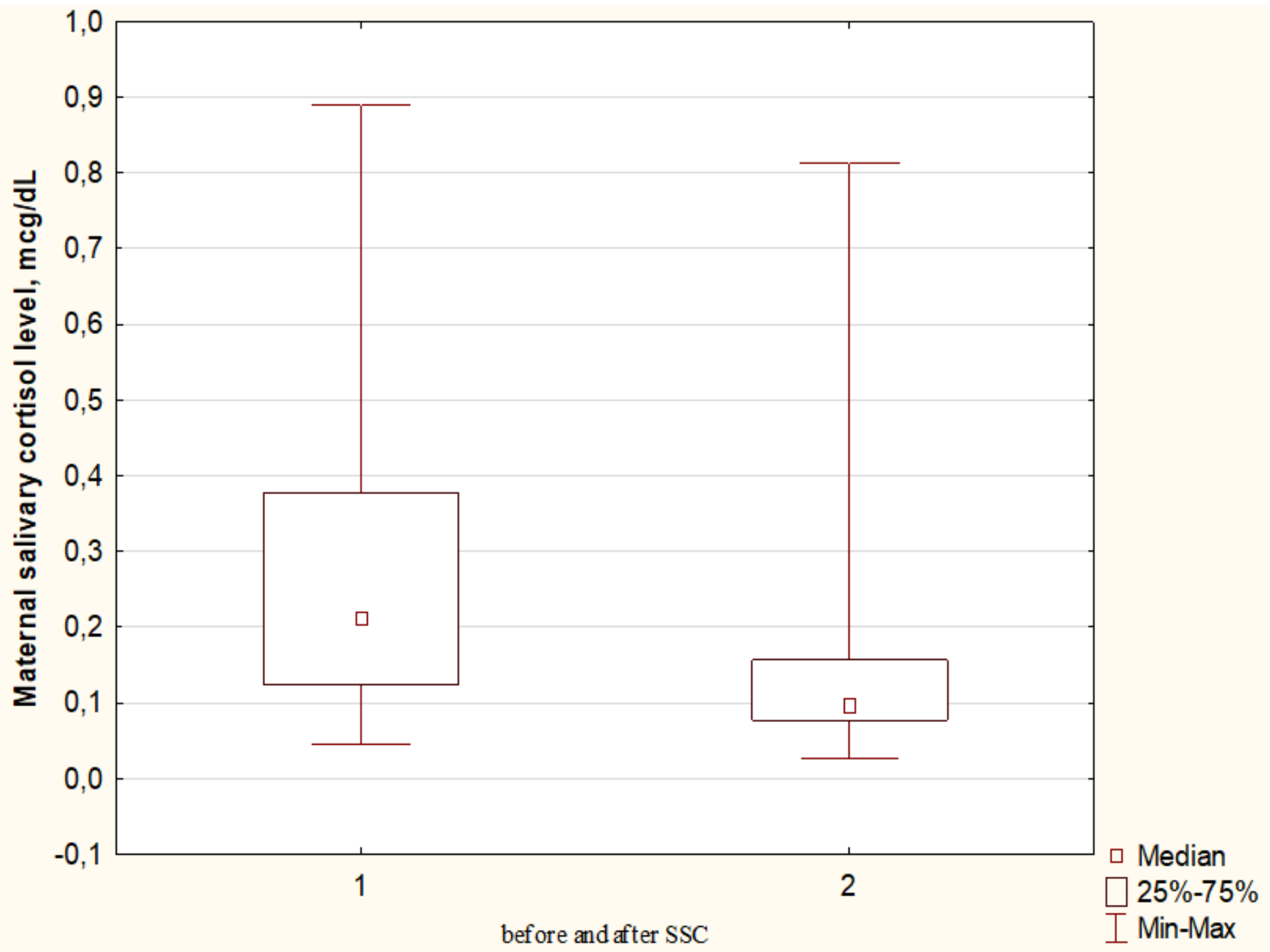

Figure 6

Maternal salivary cortisol levels before and after skin-to-skin contact 